\title{
Effect of Dietary Habits on Menstrual Problems in Young Girls
}

\author{
Mumal Singh ${ }^{1}$ and Nikita Wadhawan ${ }^{2 *}$ \\ ${ }^{1}$ CCAS, MPUAT, Udaipur, India \\ ${ }^{2}$ CDFST, Udaipur, India \\ *Corresponding author
}

\begin{tabular}{|l|}
\hline Ke y w o r d s \\
$\begin{array}{l}\text { Menstruation, Junk } \\
\text { foods, Skipping of } \\
\text { meals }\end{array}$ \\
\hline Article Info \\
\hline $\begin{array}{l}\text { Accepted: } \\
\text { 04 June } 2019 \\
\text { Available Online: } \\
\text { 10 July } 2019\end{array}$ \\
\hline
\end{tabular}

\section{A B S T R A C T}

\section{Introduction}

Dietary habits are fundamental factors that influence human life styles and individual Quality Of Life (QOL). Dietary habits and choices play a significant role in the quality of life, health and longevity. It can define cultures and play role in religion. Dietary habits in young women may determine their QOL in subsequent middle or old age and should be evaluated from the perspective of total benefit throughout whole life (Fujiwara and Nakata, 2004; Fujiwara et al., 2007; Cerin et al., 1993). Changes in food habits can cause inadequate intake of calories, micronutrients, unsaturated fat, phyto-estrogens and fiber as well as increasing environmental toxins. These factors are speculated not only to influence the present lifestyle, but also to induce gynaecologic disorders such as dysmenorrhoea and irregular menstruation (Fujiwara and Nakata, 2004; Berkey et al., 
2003; Abalkhail and Shawky, 2002). The wide spread consumption of fat food, skipping food intake and shift from local food to western foods are increasing among the young women. The list of menstrual disorders may range from amenorrhea, irregular cycles and abnormal flow to dysmenorrhoea and premenstrual symptoms (Campbell and McGrath, 1997). So it is important to evaluate the present situation of eating habit in young women and estimate their influence on menstrual cycle (Fujiwara et al., 2007). Schweiger et al., (1992) reported that daily eating habits significantly influence menstrual functions in young women. Fujiwara, (2003) found that young women who skip breakfast have a significantly higher degree of dysmenorrhoeal symptoms than young women who eat breakfast, suggesting a positive correlation between skipping breakfast and menstrual disorders.

\section{Objective}

This study was designed to study and determine the prevalence of menstrual irregularities in young girls and also to study the effect of consumption of junk foods and dietary habits on the menstrual health of girls.

\section{Materials and Methods}

The present study was carried out among young girls (16-18 years) facing menstrual problems through a survey conducted during July-18 to September-18. A prior permission was obtained from the school/college authority and the girls were selected by purposively sampling method girls were selected from Government Girls School, Pacific Business School, Keva Centre, Arts College (MLSU), Gayatri Institute of Nursing and Pacific Medical College of Udaipur district, Rajasthan. Data was collected with the help of a predesigned and pretested selfadministered questionnaire (Appendix-I). The questions were administered in English and properly explained to avoid any form of misunderstanding and to facilitate accurate response by the subjects. The interview was conducted in Hindi and also in local dialects as and when needed. Total 100 girls were selected for the study as they were facing menstrual problems. Data was analyzed as percentage of responses. The question contained items regarding variables such as dietary habits, like consumption of junk foods, consumption of fruits and vegetables, skipping of meals, age of menarche, menstrual pattern, dysmenorrhoea, regularity and average duration of menstrual cycle. They were also asked whether they had consulted a gynaecologist on any earlier occasion regarding menstrual problems.

\section{Results and Discussion}

The menstrual cycle is the hormonal driven cycle; Day 1 is the first day of your period (bleeding) while day 14 is the approximate day you ovulate and if an egg is not fertilized, hormone levels eventually drop and at about day 25; the egg begins to dissolve and the cycle begins again with the period at about day 30. Menstruation begins day 1 and normally ends days 3-5 of the menstrual cycle (https://www.medicinenet.com/menstruation/a rticle.htm).

Normal menstrual cycle was defined as a menstrual cycle lasting for 26-29 days and irregular menstruation was defined as any subjects with the length of $\leq 25$ or $\geq 30$ days (Audhi Lakshmi, 2013). It was observed that menstrual cycle was regular in $39(39.0 \%)$ respondents and irregular menstrual cycle was found in $61(61.0 \%)$ respondents. It was also observed that $60(60.0 \%)$ respondents had painful menstrual flow, out of which 31 $(31.0 \%)$ students had severe pain, $22(22.0 \%)$ had moderate pain while $07(07.0 \%)$ had mild pain. 
Table 1 reveals the distribution of young girls according to age of menarche in which only 7 per cent respondents were in age of 10. Age of menarche of 11 years were 10 per cent respondents, 33 per cent respondents age of menarche was 12 , majority of respondents i.e. 33 per cent age of menarche was 13 years and remaining 14 per cent were in age of 14 years during their first period.

The general dietary pattern of the subjects were recorded and it was found 81 per cent respondents consumed junk food, whereas 19 per cent respondents did not consumed junk food, also it was found that mainly breakfast, lunch, tea/coffee and dinner was taken as meal and majority of respondents skip one meal a day. Majority $(80 \%)$ of respondents were not regular in taking meals i.e. breakfast, 72 per cent respondents skipped breakfast, though they were not having enough time due to their school/college hours, 6 per cent skipped lunch and dinner was skipped by 2 per cent respondents. Majority of respondents (78\%) were not taking snacks between meals, only 22 per cent respondents were taking snacks between meals like biscuits, namkeen, kurkure, chips, mathries etc. Some girls were on dieting i.e. 8 per cent of respondents were dieting regularly to look more slim and attractive, majority of girls (90\%) were not dieting. Also 62 per cent girls were in habit of tea/ coffee consumption. (Table 1.1)

Table 1.2 indicates that majority $(69 \%)$ of respondents were vegetarian, 13 per cent respondents were ovo -vegetarian while 18 per cent respondents were non - vegetarian. Similarly, Chaturvedi et al., (2017) conducted a study in which 117 were vegetarians and remaining 183 were non-vegetarians.

Table 1.2 stats that 45 per cent respondents were consuming green leafy vegetables like spinach, fenugreek etc less than once a week, 31 per cent were consuming 1-2 times per week, 14 per cent respondents were consuming 3-7 days per week, 7 per cent consuming occasionally and only 3 per cent respondents were not consuming green leafy vegetables.

31 per cent respondents were consuming fresh fruits less than once a week, 38 per cent were consuming 1-2 times per week, 21 per cent respondents were consuming 3-7 days per week, 3 per cent consuming occasionally and no one comes in category of not consuming.

Table 2 indicates that 8 per cent girls were on dieting and having irregular periods, 92 per cent respondents were not doing dieting. There is significant $(p<0.05)$ relation between menstrual problem and dieting.

Adolescents tended to try to lose body weight by dietary restriction for cosmetic purpose. In Japanese young women, more than $60 \%$ college students used diet control to reduce weight despite a normal or low body mass index (Fujiwara, 2007).

Table 3 stats that 42 per cent girls consumed junk food and were having irregular periods, There is a significant $(\mathrm{p}<0.001)$ association between junk food consumption and menstrual problem. Table 4 reveals that 61 girls were not having regular meals and their periods are also irregular, while only 22 girls took regular meal and their periods were also regular, hence there is a significant $(\mathrm{p}<0.001)$ relationship between regularity of meals and regularity of periods.

Table 5 indicates that Prevalence of dysmenorrhoea among the respondents in the present study was $74 \%$ out of them 43 per cent were having severe pain, 23 were having moderate while 8 girls were facing mild pain, compared to $79.8 \%$ reported by Sangwan and Vashisht (2017), similarly, Kural et al., reported the prevalence to be $84.2 \%$. 
Table.1 Distribution of adolescents according to age of menarche

\begin{tabular}{|c|c|c|}
\hline Age of Menarche & Number & Percent (\%) \\
\hline $\mathbf{1 0}$ & 7 & 7.00 \\
\hline $\mathbf{1 1}$ & 10 & 10.00 \\
\hline $\mathbf{1 2}$ & 33 & 33.00 \\
\hline $\mathbf{1 3}$ & 36 & 36.00 \\
\hline $\mathbf{1 4}$ & 14 & 14.00 \\
\hline Total & 100 & 100.00 \\
\hline
\end{tabular}

Table.1.1 Dietary habits of the subjects

\begin{tabular}{|c|c|c|c|}
\hline S. No & Particulars & Yes & No \\
\hline 1. & $\begin{array}{c}\text { Junk food consumption } \\
\text { habit }\end{array}$ & 81 & 19 \\
\hline 2. & Regular in taking meals & 22 & 78 \\
\hline $\mathbf{3 .}$ & $\begin{array}{c}\text { Skipped Meals } \\
\text { Breakfast }\end{array}$ & 20 \\
\hline & Lunch & 72 & \\
\hline & Dinner & 2 & 78 \\
\hline $\mathbf{4 .}$ & Snacks between meals & 22 & 92 \\
\hline $\mathbf{5 .}$ & Dieting & 8 & 38 \\
\hline 6. & Tea/ Coffee consumption & 62 & \\
\hline
\end{tabular}

Table.1.2 Eating food habits

\begin{tabular}{|c|c|c|}
\hline Eating food habit & Number & Percentage (\%) \\
\hline Vegetarian & 69 & 69.00 \\
\hline Ovo - vegetarian & 13 & 13.00 \\
\hline Non - vegetarian & 18 & 18.00 \\
\hline
\end{tabular}

Table.1.3 Frequency pattern of fruits and vegetables consumption

\begin{tabular}{|l|c|c|}
\hline Particular & Number & Percentage (\%) \\
\hline Consumption of green leafy & & \\
vegetables & & 45.00 \\
Less than once a week & 45 & 31.00 \\
1-2ntimes a week & 31 & 14.00 \\
3-7 times a week & 14 & 07.00 \\
Occasionally & 07 & 03.00 \\
Not consuming & 03 & \\
\hline Consumption of fruits & 31 & 31.00 \\
Less than once a week & 38 & 38.00 \\
1-2ntimes a week & 21 & 21.00 \\
3-7 times a week & 10 & 10.00 \\
Occasionally & 0 & 0.00 \\
Not consuming & & \\
\hline
\end{tabular}


Table.2 Menstrual problems and dieting

\begin{tabular}{|c|c|c|c|c|c|c|c|}
\hline \multirow{3}{*}{$\begin{array}{l}\text { Period } \\
\text { Regular? }\end{array}$} & \multicolumn{4}{|c|}{ On Dieting? } & \multirow[t]{3}{*}{ Chi Sqr } & \multirow[t]{3}{*}{ df } & \multirow[t]{3}{*}{ Result } \\
\hline & \multicolumn{2}{|l|}{ No } & \multicolumn{2}{|c|}{ Yes } & & & \\
\hline & No & $\%$ & $\mathbf{N}$ & $\%$ & & & \\
\hline No & 53 & 57.61 & 8 & 100.00 & \multirow[t]{3}{*}{5.560} & \multirow[t]{3}{*}{1} & \multirow[t]{3}{*}{$*$} \\
\hline Yes & 39 & 42.39 & 0 & 0.00 & & & \\
\hline Total & 92 & 100.00 & 8 & 100.00 & & & \\
\hline
\end{tabular}

Table.3 Menstrual problems and consumption of junk food

\begin{tabular}{|l|l|l|l|l|l|l|l|}
\hline \multirow{2}{*}{$\begin{array}{l}\text { Consume } \\
\text { Junk Food }\end{array}$} & \multicolumn{4}{|l|}{ Regularity of Period } & Chi & df & Result \\
\cline { 2 - 6 } & No & Sqr & & \\
\cline { 2 - 6 } & No & $\%$ & N & $\%$ & & & \\
\hline No & 19 & 31.15 & 0 & 0.00 & 14.997 & 1 & $* * *$ \\
\hline Yes & 42 & 68.85 & 39 & 100.00 & & & \\
\hline Total & 61 & 100.00 & 39 & 100.00 & & & \\
\hline
\end{tabular}

Table.4 Menstrual problems and regularity of meal

\begin{tabular}{|c|c|c|c|c|c|c|c|}
\hline \multirow{3}{*}{$\begin{array}{l}\text { Take } \\
\text { Regular } \\
\text { Meal }\end{array}$} & \multicolumn{4}{|c|}{ Regularity of Periods } & \multirow[t]{3}{*}{ Chi Sqr } & \multirow[t]{3}{*}{ df } & \multirow[t]{3}{*}{ Result } \\
\hline & \multicolumn{2}{|l|}{ No } & \multicolumn{2}{|c|}{ Yes } & & & \\
\hline & No & $\%$ & $\mathbf{N}$ & $\%$ & & & \\
\hline No & 61 & 100.00 & 17 & 43.59 & \multirow[t]{3}{*}{44.116} & \multirow[t]{3}{*}{1} & \multirow[t]{3}{*}{$* * *$} \\
\hline Yes & 0 & 0.00 & 22 & 56.41 & & & \\
\hline Total & 61 & 100.00 & 39 & 100.00 & & & \\
\hline
\end{tabular}

Table.5 Distribution of respondents by pain during menstruation

\begin{tabular}{|c|c|c|}
\hline Particular & Yes & No \\
\hline Abdominal pain & 74 & 40 \\
Severe & 43 & - \\
Moderate & 23 & - \\
Mild & 08 & - \\
\hline
\end{tabular}

Table.6 Distribution of Respondents by Duration of Menstrual flow

\begin{tabular}{|c|c|c|}
\hline Duration of flow & No. of respondents & Percentage \\
\hline $\mathbf{3}$ days & 18 & 18.00 \\
\hline $\mathbf{3 - 5}$ days & 52 & 52.00 \\
\hline $\mathbf{7}$ days & 30 & 30.00 \\
\hline
\end{tabular}


Table.7 Distribution of respondents taken consultation from gynaecologist

\begin{tabular}{|c|c|}
\hline \multicolumn{2}{|c|}{ Consultation from gynaecologist } \\
\hline Yes (Percent \%) & No (Percent \%) \\
\hline $\mathbf{2 0}(\mathbf{2 0 . 0 0 \%})$ & $80(80.00 \%)$ \\
\hline
\end{tabular}

Table 6 describes the duration of menstrual flow of respondents that 18 per cent girls were having $\leq 3$ days, majority of respondents $(52 \%)$ were having duration flow between $>3$ 5 days and 30 per cent respondents were having $\geq 7$ days duration of menstrual problem.

Table 7 indicates that majority $(80 \%)$ respondents had not taken consultation from gynaecologist and only 20 per cent respondents had taken consultation from gynaecologist.

In the present study we attempted to find a relation between various dietary habits like eating of junk foods, fruits, vegetables, skipping of meals on the menstrual cycle of young girls. In our study we find a significant association between irregular meals and menstrual cycle which might be due to skipping of meals mostly like breakfast, Similarly Fujiwara et al., 2009 reported that skipping of breakfast had adverse effect on menstrual cycle in young girls. Fujiwara and Nakata in 2010 studied and reported that skipping of breakfast is associated with reproductive dysfunction in post-adolescent female college students found the incidence of irregular menses was higher in the population that skipped breakfast. On the other hand gynaecologic disorders such as dysmenorrhoea and irregular menstruation were associated with food intake problems. (Fujiwara and Nakata, 2004)

In the study we noticed that $61(61.0 \%)$ respondents took junk food, significant association $(\mathrm{p}<0.001)$ was observed between consumption of junk food and menstrual cycle, Similar result was also reported by Rupavani et al., (2013). Junk foods being deficient in micronutrients like vitamin B6, calcium, magnesium and potassium might be responsible for triggering premenstrual symptoms (Rupavani et al., 2013), whereas Nirmala et al., (2014) reported a significant association between irregular menstrual cycles, abnormal flow, dysmenorrhoea and PMS with frequent consumption of junk food. This study also signifies 74 per cent respondents were facing dysmenorrhoeal problems out of them 43 per cent were having severe pain, 23 were having moderate while 8 girls were facing mild pain. Duration of menstrual flow of respondents that 18 per cent girls were having $\leq 3$ days, majority of respondents $(52 \%)$ were having duration flow between >3-5 days and 30 per cent respondents were having $\geq 7$ days duration of menstrual problem.

The differences in inter-menstrual interval and duration of flow could be because of different lifestyle, dietary habits, stress, hormonal imbalance or some medical reasons which require gynaecological assessment.

In the present study it was observed that majority of the respondents had irregular menstrual cycle and there was significant association between dietary habits and menstrual cycle. Many other studies had reported the adverse effect of dietary habits on the menstrual cycle. So further study is required with a large sample size. Healthy dietary habits like decreasing the intake of junk foods and promoting healthy eating habits should be emphasised to improve menstrual health of young college girls. 


\section{References}

Abalkhail, B. and Shawky, S. 2002. Prevalance of daily breakfast intake, iron deficiency anaemia and awareness of being anaemic among Saudi school students. International Journal of Food Science and Nutrition. 53(6): $519-528$.

Audhi lakshmi S. (2013). Impact of life Style and dietary habits on menstrual cycle of college students. International Journal of Science and Research (IJSR), 4(4): 2845-2847.

Berkey, C.S., Rockett, H.R., Gillman, M.W., Field, A.E. and Colditz, G.A. 2003. Longitudinal study of skipping breakfast and weight change in adolescents. International Journal of Obesity and Related Metabolic Disorders. 27(10): 1258 -1266.

Campbell M. and McGrath P. Use of medication by the adolescents for the management of menstrual discomfort. Arch Pediatr Adolesc Med 1997; 151(9): 905-912.

Cerin A., Collins A., Landgren BM. and Eneroth P. Hormonal and biochemical profiles of premenstrual syndrome. Acta Obstet Gynecol Scand 1993; 72: 33743.

Charturvedi, D., Chaudhuri, K.P., Chaudhary, K.A. (2017). Study of correlation between dietary habits and anemia among adolescent girls in Ranchi and its surrounding area. International Journal of Contemporary and Pediatrics. 4(4): 1165-1168.

Davis C. P. 2018. Menstruation (Cycle, Period) Symptoms, Definition, Cycle length, Irregular Bleeding Retrieved from

https://www.medicinenet.com/menstrua tion/article.htm on 25th January, 2019.

Fujiwara T. 2007. Diet during adolescence is a trigger for subsequent development of dysmenorrhea in young women.
International Journal of Food Science and Nutrition. 58 (6): 437 - 444.

Fujiwara T. and Nakata R. (2004) Skipping breakfast is associated with reproductive dysfunction in post adolescent female college students. J. Appet 2010; 55(3): 714-7.

Fujiwara, T., Sato, N., Awaji, H. and Nakata, R. 2007. Adverse Effects of Dietary Habits on Menstrual Disorders in Young Women. The Open Food Science Journal. 1: 24 - 30.

Kural, M., Noor, N., Pandit, D., Joshi, T. and Patil, A. 2015. Menstrual characteristics and prevalence of dysmenorrhea in college going girls. Journal of Family Medicine and Primary Care. 4 (3): 426431.

Lee L.K., Chen P.C.Y and Kaur, (2006) J. Menstruation among adolescent girls in Malaysia; a cross-sectional school survey. Singapore Medical Journal. 47(10): 869-74.

Nirmala Jaget Lakkawar., Jayavani R.L., Nivedhana Arthi P., Padma Alaganandam and Vanajakshi N. (2014). A Study of Menstrual Disorders in Medical students and its correlation with Biological Variables. Scholars Journals of Applied Medical Sciences. 2(6): 3165-3175.

Rupavani K., Veena K.S., Subitha L., Hemanth Kumar V.R. and Bupathy A. (2013). Menstrual abnormalities in school going girls - Are they related to Dietary and Exercise pattern? Journal of Clinic and Diagnostic Research. $7(11)$.

Sangwan, G. and Vashisht, B.M. 2017. Menstrual pattern and prevalence of dysmenorrhea among school going adolescent girls in a rural block of Haryana: A cross sectional study. Global Journal of Medicine and Public Health. 6 (2): 1 - 5. 
Schweiger U., Tuschl R.J., Platte P., Broocks A., Laessle R.G. and Pirke K.M. Everyday eating behavior and menstrual function in young women. Fertil Steril 1992; 57(4):771-5.
Sharma P, Malhotra C, Taneja DK, Saha R. (2008). Problems related to menstruation amongst adolescent girls. Indian Journal of Pediatritics; 75(2): $125-9$.

\section{How to cite this article:}

Mumal Singh and Nikita Wadhawan. 2019. Effect of Dietary Habits on Menstrual Problems in Young Girls. Int.J.Curr.Microbiol.App.Sci. 8(07): 279-286.

doi: https://doi.org/10.20546/ijcmas.2019.807.035

\section{Dietary food habits (Appendix-I)}

1) How many meals do you take in a day?

Breakfast: -

Lunch: -

Tea/Coffee: -

Dinner: -

2) Do you have snacks in between meals? Yes / No

If yes than type of snacks in between meals

3) What is your eating food habits?

a) Vegetarian b) Non- Vegetarian c) OvoVegetarian

3) Do you consume junk food/ fast food?
a) Yes
b) No

4) Are you regular in taking meals? Yes / No

If No, then mention which meal you skip? Breakfast / Lunch / Dinner

Reason of skipping meals, please specify

6) Are you on dieting?
a) Yes
b) $\mathrm{No}$

If yes, than what is the reason of dieting?

i) To look more slim and attractive ii) To avoid meals due to mood swings

iii) Due to liking and disliking meals

iv) Any other (Please specify -----------------)

\section{Information related to Menstrual Cycle}

1) Age of menarche (when you experience your first period?

2) Are your periods regular?
a) Yes
b) No

3) Duration of menstrual flow? (how many days do you bleed for?)
a) $\leq 3$ days
b) >3-5 days
c) $\geq 7$ days

4) You are facing pain during menstruation?
a) Yes
b) No

If yes, than what is the location of your pain?

What is the severity of your pain?

5) Have you ever taken consultation from gynaecologist regarding menstrual problem?
a)Yes
b) No 